\title{
Polêmicas contemporâneas sobre o método científico: uma revisão sistemática da literatura
}

Contemporary controversies about the scientific method: a systematic review of the literature

Naiana Ribeiro Maximilla ${ }^{1}$

Lavínia Schwantes ${ }^{2}$

\section{Resumo}

A ciência, desde sua emergência como a conhecemos, entre os séculos XVI e XVII, vem ocupando um lugar de destaque cada vez maior na sociedade humana. Sendo frequentemente referida e definida como a fonte da verdade e produtora de fatos incontestáveis, tornou-se aos poucos isenta de contestações. O método científico se funde com a ciência moderna, mas pouco se discute sobre suas possíveis limitações práticas e epistemológicas - justamente por esse ser um termo já naturalizado e que sustenta a metanarrativa científica. No imaginário coletivo, o método científico é o que confere legitimidade à ciência e sua produção de verdades. No presente trabalho, nosso objetivo foi investigar na literatura estudos que problematizassem o método científico na contemporaneidade. De 205 artigos recuperados na busca, apenas sete problematizavam o método científico. Todos os trabalhos eram em língua estrangeira e articulavam questionamentos sobre o método com a educação científica. Os artigos recuperados concordaram em alguns aspectos: o método científico não é universal; não segue etapas pré-definidas e não é linear. Ao contrário, segundo os autores, a investigação científica é complexa, depende da criatividade do pesquisador e, muitas vezes, a objetividade almejada com tal método pode limitar o processo da investigação.

Palavras-chave: Método científico; Filosofia da Ciência; História da Ciência; Ensino de Ciências.

\section{Abstract}

Science, since its emergence as we know it, between has occupied an increasingly prominent place in human society. Often referred to and defined as the source of truth and the producer of unquestionable facts, gradually became free from contestation. The scientific method merges with modern science, but little is discussed about its possible practical and epistemological limitations precisely because it is a term already naturalized and that supports the scientific metanarrative. In the collective imaginary, the scientific method is what gives legitimacy to science and its production of truths. In the present work, our objective was to investigate in the literature studies that problematized the scientific method in contemporaneity. We retrieve 205 articles in the search and only seven problematized the scientific method. All the works were in a foreign language (not portuguese) and articulated questions about the method with scientific education. The retrieved articles agreed on some aspects: the scientific method is not universal; does not follow predefined steps and is not linear. On the contrary, according to the authors, scientific research is complex, depends on the creativity of the researcher, and often the objectivity desired by such a method may limit the research process.

Keywords: Scientific method; Philosophy of Science; History of Science; Science Education.

\footnotetext{
1 Universidade Federal do Rio Grande | naianamaximilla@hotmail.com

2 Universidade Federal do Rio Grande | laviniasch@gmail.com
} 


\section{Introdução}

A educação científica tem como um dos seus aspectos fundamentais, a alfabetização científica dos sujeitos. Através do conhecimento e do raciocínio científico, é possível que os sujeitos identifiquem e respondam a questões cotidianas, conheçam a si mesmos e ao mundo e participem de pautas públicas sobre ciência, tecnologia e sociedade (CHASSOT, 2010).

Atualmente, muito se tem discutido sobre as abordagens de ensino de ciências em sala de aula que, ainda hoje, focam na transmissão de "fatos científicos", como conhecimentos descontextualizados social e historicamente (KRASILCHIK, 2007). Recomenda-se, entre outras ideias, que para, de fato, haver a alfabetização científica dentro das salas de aula, essas abordagens se aproximem de discussões sobre a prática científica e seus efeitos na sociedade contemporânea (FARIAS et al, 2012).

A ciência, desde sua emergência entre os séculos XVI e VII, gradativamente se tornou isenta de contestações por ser identificada como produtora de fatos verdadeiros e, portanto, incontestáveis. Como podemos perceber atualmente, ideias e produtos tentam se legitimar através da justificativa científica: basta algo ser provado cientificamente para ser aceito (CHALMERS, 1993).

Atentos a isso, estudiosos no início da década de 1960, percebendo a influência política e cultural da ciência sobre a sociedade, começaram a realizar inúmeros estudos sobre a produção científica e sobre os desdobramentos da prática científica no âmbito social. Lyotard (2002), por exemplo, escreveu sobre o que ele denomina "condição pós-moderna", destacando que as transformações de ordem cultural pelas quais passa a sociedade contemporânea envolvem o fim das metanarrativas. Consequentemente, segundo ele, os grandes esquemas explicativos teriam caído em descrédito e não haveria mais "garantias", posto que mesmo a ciência já não poderia ser considerada como a única fonte da verdade.

A partir dessa perspectiva, podemos investigar e estudar a ciência no intuito de analisar as características que permitiram que ela se tornasse uma metanarrativa: um dogma contemporâneo. Para tanto, precisamos impreterivelmente discutir sobre um dos seus aspectos mais importantes - e o menos discutido: o método científico.

Pouco se questiona acerca do método científico, justamente por esse ser o método que sustenta a metanarrativa científica. $O$ método científico é o que confere legitimidade à ciência e sua produção de verdades. Justamente por isso, é necessário problematizarmos o conceito de um método científico. Alguns trabalhos rejeitam a ideia de um método universal na ciência, com passos pré-definidos e rígidos capaz de "produzir" a ciência (MCCOMAS, 1996; MOREIRA e OSTERMANN, 1993; NUMBERS, KAMPOURAKIS, 2015).

Através de um estudo histórico, identificamos que nenhum dos ditos "pais" do método científico (Bacon, Descartes, Newton, por exemplo) de fato definiu ou seguiu tais passos, como esses difundidos atualmente (CHALMERS, 1993; FEYERABEND, 2007). Pelo contrário: pode-se averiguar que apesar de muitos filósofos terem realizado estudos sobre o método científico, não foram esses que popularizaram o processo. Ao que parece, esse "o método científico", em etapas foi resultado dos esforços de profissionais da educação científica, nos Estados Unidos, no início do século XX, durante a reforma educacional que ocorreu nas quatro primeiras décadas no país. Talvez, por ser uma iniciativa da área da educação, o método científico tenha sido amplamente difundido e com sucesso, vigorando em livros didáticos e de divulgação científica até os dias atuais (RUDOLPH, 2005). 
O ensino do método científico, atualmente, toma para si e resume superficialmente o que de fato é o processo científico ou investigação científica. Segundo Loor (2015), o termo "método científico" trata-se de uma infeliz metonímia, isto é, uma figura de linguagem que possibilita troca de um termo por outro de mesma similaridade. Para o autor, não existe "o método científico" e sim a investigação científica na qual se emprega inúmeros métodos.

Um dos mais conhecidos pensadores na história e filosofia da ciência, Paul Feyerabend, ocupou considerável parte de sua produção intelectual com argumentos que rejeitavam a ideia de um método universal na ciência. Em seu livro Contra o Método (2011), Feyerabend diz que:

A ideia de conduzir os negócios da ciência com o auxílio de um método que encerre princípios firmes, imutáveis e incondicionalmente obrigatórios vê-se diante de considerável dificuldade, quando posta em confronto com os resultados da pesquisa histórica. Verificamos, fazendo um confronto, que não há uma só regra que deixe de ser violada em algum momento. (FEYRABEND, 2011, p. 29)

Para Feyerabend, qualquer "método prescritivo" poderia limitar a atividade de cientistas. O autor afirma que a ciência só faria se beneficiar de uma "dose" de anarquismo, pois esse sistema seria o mais humanitário e menos determinístico.

Com base no que foi apresentado, o objetivo do presente trabalho é realizar uma revisão da literatura acadêmica, a fim de conhecer trabalhos que questionem ou problematizem a existência do método científico. Ainda destacamos que a presente investigação faz parte de uma pesquisa maior, a qual procura problematizar como o método científico vem sendo trabalhado na formação de professores, através da produção científica.

\section{Metodologia}

A revisão sistemática da literatura é, atualmente, uma etapa imprescindível da investigação científica. Devido ao grande número de publicações científicas disponíveis, a revisão deixa de ser uma possibilidade para tornar-se uma necessidade: seja para construir a contextualização para o problema de análise, seja para analisar as produções presentes na literatura (VOSGERAU; ROMANOWSK, 2014).

Para realizar uma revisão sistemática é necessário, primeiramente, estabelecer a estratégia de busca nas bases de dados. A nossa estratégia começou ao definirmos a pergunta da pesquisa, o objetivo. A pergunta da presente pesquisa é: O método científico tem sido objeto de questionamento em artigos recentemente publicados em periódicos científicos? O que tem sido discutido nesses artigos?

Após estabelecer o objetivo, escolhemos quais fontes investigaríamos: Portal de Periódicos da CAPES, SciELO (Scientific Electronic Library Online) e no Portal ScienceDirect. Para prosseguir, precisamos escolher as palavras-chave. É comum testar várias combinações e realizar buscas de teste, para avaliar se o material recuperado se enquadra no recorte da pesquisa. Nessa pesquisa, decidimos usar apenas as palavras-chave "método científico" e "scientific method" e restringimos a busca apenas para artigos que continham as palavras no título - as aspas são necessárias para a busca retornar somente o termo unido, caso 
contrário, seriam recuperados todos os artigos que possuíam qualquer combinação das duas palavras utilizadas.

Ainda na estratégia de busca, é necessário avaliar quais operadores boolenos serão utilizados. Os operadores booleanos delimitam a busca, sendo necessário saber utilizá-los. Como pesquisamos apenas um termo, mas em idiomas diferentes, precisamos apenas do operador 'OR', para recuperar documentos que discutiam método científico. O período de publicações analisadas foi de 2008-2018 e não restringimos a busca a nenhuma área do conhecimento, pois julgamos importante analisar o que está sendo discutido e comparar as pesquisas de diferentes campos de estudo. Por fim, foram escolhidos apenas documentos no formato de artigos e que pertenciam a periódicos revisados por pares. Para melhor visualização da estratégia de busca, foi organizado o Quadro 1.

\begin{tabular}{|c|c|c|c|c|c|c|}
\hline $\begin{array}{c}\text { Fontes de } \\
\text { dados }\end{array}$ & $\begin{array}{c}\text { Palavras- } \\
\text { chave }\end{array}$ & $\begin{array}{l}\text { Parte do } \\
\text { texto }\end{array}$ & $\begin{array}{c}\text { Operadores } \\
\text { booleanos }\end{array}$ & $\begin{array}{c}\text { Período de } \\
\text { produção } \\
\text { analisado }\end{array}$ & Idiomas & $\begin{array}{l}\text { Outros } \\
\text { filtros }\end{array}$ \\
\hline $\begin{array}{c}\text { Portal de } \\
\text { Periódicos da } \\
\text { CAPES } \\
\text { SciELO } \\
\text { ScienceDirect }\end{array}$ & $\begin{array}{l}\text { Método } \\
\text { científico } \\
\text { Scientific } \\
\text { method }\end{array}$ & $\begin{array}{l}\text { Palavras- } \\
\text { chave } \\
\text { presente no } \\
\text { título }\end{array}$ & $\begin{array}{c}\text { Aspas ("'I) e } \\
\text { OR }\end{array}$ & 2008-2018 & $\begin{array}{c}\text { Português } \\
\text { Espanhol } \\
\text { Inglês }\end{array}$ & $\begin{array}{l}\text { Somente } \\
\text { artigos; } \\
\text { Periódicos } \\
\text { revisados } \\
\text { por pares; }\end{array}$ \\
\hline
\end{tabular}

Quadro 1: Desenvolvimento da estratégia de busca

Na primeira fase da revisão, analisamos o título e o resumo de todos os artigos recuperados na busca e aqueles que se enquadram no que é investigado são selecionados. Contudo, alguns artigos podem deixar dúvidas devido a ambiguidades ou pouca informação no resumo, nesse caso também são selecionados. Logo, há uma segunda etapa que consiste na leitura completa dos artigos selecionados, e nessa fase também podem ser excluídos artigos por não se adequarem ao tema.

Não foram selecionados os artigos científicos que assumiam o método científico como o conhecido processo linear de: observação, formulação de hipótese, experimentação e conclusão, pois o objetivo foi analisar, justamente, trabalhos que discutam o método de uma forma diferenciada, trabalhos que estejam afastados da abordagem usual do método.

Após apresentar os resultados quantitativos da pesquisa, serão feitas discussões sobre as ideias principais de cada um desses textos, a fim de contextualizar os achados para os leitores.

\section{Resultados e discussão}

\section{Primeira etapa da revisão sistemática}

Na primeira etapa da pesquisa, como pode ser visto no quadro 2, no Portal de Periódicos da Capes foram recuperados 168 artigos; contudo, somente 15 foram selecionados. Na Scielo, foram encontrados 17 artigos e no ScienceDirect foram encontrados 31 artigos, mas nenhum artigo foi selecionado nessas duas bases de dados (Quadro 2). 


\begin{tabular}{c|c|c|c|c}
\hline Fonte de dados & Termos de Busca & $\begin{array}{c}\text { Campo } \\
\text { de busca }\end{array}$ & $\begin{array}{c}\text { Doc. } \\
\text { Rec. }\end{array}$ & Doc. Sel. \\
\hline $\begin{array}{c}\text { Portal de Periódicos da } \\
\text { CAPES }\end{array}$ & "método científico" OR "scientific method" & Título & 168 & 15 \\
\hline SCIELO & "método científico" OR "scientific method" & Título & 6 & 0 \\
\hline ScienceDirect & "método científico" OR "scientific method" & Título & 31 & 0 \\
\hline
\end{tabular}

Quadro 2. Resultado da pesquisa nas diferentes fontes de dados

Os motivos para a exclusão de 190 artigos nessa primeira fase foram os seguintes: artigos que assumiam a existência de um método científico único e linear, visando a aplicação do método na sua área de estudo, como: saúde, robótica, sociologia, literatura, ciência da informação, biologia, educação científica, entre outras (151), artigos repetidos (24), resenhas e livros que passaram pelo filtro "somente artigos" (12) e artigos em linguagem que não português, inglês ou espanhol (3).

\section{Segunda etapa da revisão sistemática: artigos selecionados}

Na segunda etapa da revisão, os 15 artigos selecionados foram lidos integralmente para avaliar se o desenvolvimento realmente condizia com o resumo. Ao final das leituras, 8 artigos foram excluídos da seleção por não realizarem discussões problematizadoras sobre o ensino do método científico. Dessa forma, restaram 7 trabalhos finais os quais serão apresentados a seguir (Quadro 3).

\begin{tabular}{|c|c|c|c|}
\hline Autor & Ano & Título & Revista \\
\hline Brian Woodcock & 2014 & $\begin{array}{c}\text { "The Scientific Method" as Myth and } \\
\text { Ideal }\end{array}$ & Science \& Education \\
\hline Clyde F. Herreid & 2010 & $\begin{array}{l}\text { The Scientific Method Ain't What It } \\
\text { Used to Be }\end{array}$ & $\begin{array}{c}\text { Journal of College Science } \\
\text { Teaching }\end{array}$ \\
\hline Konstantinos Alexakos & 2010 & $\begin{array}{l}\text { Teaching the practice of science, } \\
\text { unteaching the "scientific method" }\end{array}$ & Science Scope \\
\hline Mauricio Castillo & 2013 & $\begin{array}{c}\text { The Scientific Method: A Need for } \\
\text { Something Better? }\end{array}$ & $\begin{array}{l}\text { American Journal of } \\
\text { Neuroradiology }\end{array}$ \\
\hline Rody A. Cedeño Loor & 2015 & El Método Científico, Una Utopía & $\begin{array}{c}\text { Revista Electrónica } \\
\text { Formación y Calidad Educativa }\end{array}$ \\
\hline $\begin{array}{l}\text { Ronald A. Brown \& } \\
\text { Alok Kumar }\end{array}$ & 2013 & The scientific method: reality or myth? & $\begin{array}{c}\text { Journal of College Science } \\
\text { Teaching }\end{array}$ \\
\hline Xiaowei Tang et al. & 2010 & $\begin{array}{c}\text { The Scientific Method and Scientific Ing } \\
\text { uiry: Tensions in Teaching and } \\
\text { Learning }\end{array}$ & Science Education \\
\hline
\end{tabular}

Quadro 3. Artigos que problematizam o método científico

Antes de discutirmos os artigos selecionados, alguns aspectos quantitativos precisam ser abordados. Primeiro, a quantidade de artigos que possuem "método científico" no título é muito menor do que a literatura que usa esse termo no desenvolvimento do seu trabalho, pois, devido à cultura científica, o termo é muito utilizado quando se está querendo justificar e legitimar o desenvolvimento dos seus estudos. A decisão de escolher somente artigos com o termo no título foi justamente para conseguir avaliar a produção de artigos que abordavam o método científico como assunto principal. Segundo, a quantidade de artigos selecionados ao final da pesquisa evidencia a carência de produção problematizando o método científico. 
Recorrendo ao quadro 3, percebemos que nenhum artigo em língua portuguesa foi selecionado. Isso ocorreu devido ao pequeno número de artigos em português que foi recuperado na pesquisa, apenas 6 trabalhos - obviamente, nenhum deles problematizou ou questionou o método. Contudo, é válido reportar que antes da segunda triagem da pesquisa, entre os 15 trabalhos inicialmente selecionados, havia um estudo brasileiro, mas não se enquadrou no tópico de interesse da presente investigação.

Entre os estudos que serão analisados, 6 dos artigos foram publicados em periódicos ou da área de educação ou da área da educação científica. Como foi mencionado na introdução desse trabalho, a popularização do método científico como etapas rígidas a serem seguidas, aparentemente, ocorreu através educação científica. É razoável que os primeiros trabalhos questionando esse método também pertençam a essa área do conhecimento. Também é compreensível que seis dos sete trabalhos sejam em língua inglesa, pois foi no início do século XX, nos Estados Unidos, que ocorreu a implementação de um currículo o qual orientava empenhadamente sobre o uso do método científico - os profissionais estadunidenses estão em contato com esse dilema há bastante tempo.

O primeiro artigo selecionado foi de Woodcock (2014), o qual procurou identificar se o método científico é válido como um ideal inalcançável, conforme explicita no título do seu artigo Scientific Method: as Myth and Ideal. O autor utilizou como ponto de partida para as discussões do seu estudo o livro Scientific Literacy and the Myth of Scientific Method (1992), de Henry H. Bauer. Nesse livro, Bauer chega à conclusão de que o método científico é um ideal inalcançável, mas defende seu uso para facilitar o entendimento sobre a prática científica. Woodcock não concorda com a conclusão de Bauer, e afirma que a noção de "o método científico" é problemática. No seu trabalho argumenta que "várias são as razões que não só justificam chamar o método científico de mito, como também várias são as razões que justificam a conclusão de que esse [método] deveria ser descartado" (WOODCOCK, 2014, p. 3). Ele também diz que, em algumas vezes alguns conceitos incompletos são úteis para facilitar aproximações, mas que não é o caso do método científico: "(...) Isso [método] engana. Faremos melhor em evitar o mito e também creio que esse não deveria ser tratado como um ideal inalcançável" (WOODCOCK, 2014, p. 5).

Woodcock analisa vários aspectos que levaram a enganosa concepção do método científico, dentre os tópicos que o autor aborda estão: "sem consenso histórico ou contemporâneo", "variação em concepções populares e de cursos introdutórios", "equívocos gerais", "estereótipo individual", "sem garantia de objetividade", "um limitado método de descobertas", "uma pintura incompleta da atividade científica", entre outros. Os últimos tópicos do trabalho revelam que, para o autor, existem muitos métodos utilizados na empreitada científica, não havendo um método único e universal. O artigo de Woodcock pode ser recomendado como um curso introdutório para quem não está familiarizado sobre os questionamentos acerca do método científico.

O segundo artigo selecionado, é de autoria de Herreid (2010), que discute uma abordagem alternativa sobre o método científico, elaborada por profissionais da Universidade de Berkeley, nos Estados Unidos, e que está disponível no website do projeto Way Science Really Works (https://undsci.berkeley.edu/index.php). Ao contrário do trabalho anterior, Herreid não defende e nem discute o abandono do método científico, mas sim o uso de uma nova abordagem, mostrando a real complexidade da investigação científica, trazendo exemplos do website mencionado. Segundo o autor, "o diferencial do modelo da Berkeley é por mostrar que a ciência não é um processo linear. O método com hipótese, 
experimento, análise de dados e conclusão é muito simples" (HERREID, 2010, p. 1). Introduzir esse último método para as pessoas pode levar a alguns equívocos como: "a ciência é uma coleção de fatos", "a ciência é completa", "há um único método científico o qual todos cientistas seguem", "o processo científico é puramente analítico e não envolve criatividade", "experimentos são uma parte necessária do processo científico", "hard sciences são mais rigorosas e científicas que as soft sciences", e muitos outros exemplos estão disponíveis na página sobre o método científico.

No fluxograma desenvolvido pelos profissionais de Berkeley, é possível notar quatro esferas (exploração e descobertas, testando novas ideias, análise da comunidade e feedback e benefícios e resultados) que se interconectam e não possuem caráter unidirecional. E há todos os tipos de "inputs" e "outputs" que são descartados quando estamos trabalhando com aquele "outro método". Por exemplo, dentre os tipos de situações que levam uma pessoa a explorar um novo assunto, estão "motivação pessoal", "serendipidade" e "observações inesperadas" - não intencionais. É interessante notar que o método científico usual só utilizaria dois dos círculos do fluxograma: "exploração e descoberta" e "testando as ideias" e de forma bem mais generalista do que mostra o fluxograma da Berkeley.

O terceiro artigo, de Alexakos (2010), trabalho intitulado Teaching the practice of science, unteaching the "scientific method", utilizou um caso científico falso para avaliar as concepções de ciência de seus alunos. Ele diz que aqueles que não identificaram os equívocos no caso em questão, utilizaram o método científico para justificar seus resultados:

O que se tornou claro através de nossas discussões foi que esses estudantes pareciam assumir que se qualquer um seguir os passos universais e pré-determinados do método científico, esse irá, automaticamente, chegar à resposta certa - não importando quão bizarra a resposta pareça ser. (ALEXAKOS, 2010, p. 1)

Ele constata que esse problema ocorre devido ao fato de que os estudantes são orientados a fazer ciência como se estivessem seguindo "receitas" para atividades laboratoriais, negando qualquer coisa estimulante ou criativa: "essas assunções e crenças ajudaram a criar e a manter um afastamento entre esses estudantes e a ciência" (ALEXAKOS, 2010, p. 1). Ele explica que esse ensino mecânico sobre a ciência, estimulou associações educativas e cientistas a, explicitamente, repudiar o conceito de "um método científico universal".

Alexakos diz que a NSTA's (National Science Teachers Association, ou Associação Nacional de Professores de Ciência), a maior organização educacional do tipo, em seus documentos que visam orientar a prática desses profissionais, defende que não existe tal método científico e que a investigação não deve ser reduzida a passos específicos, e sim ser dinâmico e ir além de procedimentos isolados. Pois, em longo prazo, são justamente as idiossincrasias pessoais e particularidades que normalmente guiam as soluções para questões científicas.

O autor também argumenta que, ao contrário do método científico que é ensinado nas escolas, muitas investigações científicas não são feitas no laboratório e nem são limitadas a observação direta. Ele traz exemplos citados por Gould (1987), como a evolução dos dinossauros em aves e a criação do Himalaia; esses fenômenos ocorreram há muito tempo no passado pra qualquer um ter visto ou ser capaz de reproduzir o ocorrido experimentalmente. Ainda assim, teorias de evolução e as placas tectônicas não são menos científicas por isso. 
Por fim, Alexakos afirma que desafios como resistência microbiana, engenharia genética e a criação de fontes alternativas de energia, não só precisam de experimentação e evidência, mas também de abordagens criativas. Então, não faz sentido ensinar somente a primeira parte para os estudantes, difundindo o método científico como "uma mitologia prejudicial".

No quarto artigo representado na tabela e intitulado Scientific Method: a need for something better?, Castillo (2013) faz uma breve retomada histórica para mostrar que o método científico como conhecemos hoje data de 1930. E apesar de sua rígida estrutura, o método depende, totalmente, de capacidades humanas como: criatividade, imaginação e inteligência.

Um interessante aspecto que o autor discute e que não foi abordado nos trabalhos até agora mencionados, diz respeito ao problema de que uma hipótese apenas reflete conhecimento estabelecido, evidências que contrariam a hipótese podem ser descartadas, limitando o avanço científico. Segundo o autor:

No método científico, resultados inesperados não são confiáveis, enquanto que aqueles previstos são imediatamente aceitos. $O$ fato de nós fazermos "isso" para observar "aquilo" pode ser um hábito muito traiçoeiro a longo prazo. Contudo, muitas controvérsias poderiam ter sido evitadas se, ao invés de chamarmos "o método científico", chamássemos de "um método científico". Alguns argumentam que esse método foi chamado de "científico" porque aquele que inventou era arrogante e pretensioso. (Castillo, 2013, p. 2).

A discussão final do artigo problematiza o fato de que a maioria das revistas não aceitam publicações que são baseados em modelos teóricos não provados, o que influencia negativamente as áreas de pesquisa relacionadas às ciências sociais. Isso leva a um acúmulo de trabalhos que se esforçam em realizar previsões ao invés de novas ideias, carecendo de enquadramentos epistêmicos relevantes para a disciplina (CASTILLO, 2013). Como podemos perceber, esse artigo difere dos anteriores por deslocar a discussão diretamente para a comunidade científica e suas normas que visam a aceitação de trabalhos considerados científicos.

Ao final do trabalho, Castillo sugere uma nova abordagem para se utilizar em estudos científicos, chamado "model-based inquiry". Esse método tenciona desenvolver diversas explicações possíveis para o objeto de estudo, e novas hipóteses, conceitos e predições podem ser gerados em qualquer ponto ao longo da investigação. $O$ autor também cita o método desenvolvido por cientistas, filósofos e educadores da Universidade de Berkeley e ressalta: "diferente do tradicional método científico, esse novo [método desenvolvido na Berkeley] aceita evidências que não se encaixam em conclusões ideais" (CASTILLO, 2013, p.4), até porque a ciência é sobre descobertas, e não apenas justificação - como parece enfatizar.

Loor (2015), no quinto artigo analisado, realizou uma entrevista com professores de metodologia de pesquisa da Universidade Eloy Alfaro de Manabí (ULEAM- México), no intuito de analisar as concepções de método científico desses profissionais.

O autor descobriu que $76 \%$ dos entrevistados acreditam que existe um método chamado científico, contra $24 \%$ que manifestam não existir o método científico, pois se trata de um processo muito simples e ingênuo. Loor afirma que para ele existem diversos métodos científicos como: método quantitativo, método qualitativo, experimental e dialético 
- entre outros. Contudo, o autor deixa claro que a intenção do artigo não é adentrar na classificação dos métodos; mas essencialmente, demonstrar que o conceito "método científico", está mal definido e, contudo, aplicado até os dias atuais.

Assim como a autora da presente pesquisa, Loor utiliza Feyerabend como referencial teórico, mostrando a importância de discutirmos o método científico tanto nas instâncias escolares quanto nas acadêmicas. Loor conclui que:

Não existe um método chamado científico, porque este carece de regras teóricas e práticas que o sustentem. O método como se concebeu não é nada mais do que regras de conduta e proposições mentais, e seu término refere-se à investigação científica e não a um método específico. (LOOR, 2015, p. 7)

Dessa forma é urgente que comecemos a falar em "métodos científicos" para tentarmos corrigir esse equívoco que insiste em perpetuar-se (FEYERABEND, 2007).

O penúltimo artigo a ser analisado é de autoria de Brown e Kumar (2013) e está intitulado como Scientific method: reality or myth?. Os autores começam o texto falando que não consideram válido o uso do método científico como metodologia de pesquisa. Afirmam que existem falhas conceituais e filosóficas graves, causando danos à credibilidade da investigação científica. Eles continuam o texto dizendo que "se nos prendermos ao método que Bacon sugeriu, devemos investigar através de um processo indutivo, no qual observações precedem hipóteses e teorias" (BROWN E KUMAR, 2013, p. 1). Contudo, assim como os autores discutem, ao analisarmos exemplos da física moderna, particularmente os trabalhos de Albert Einstein, perceberemos que a teoria precede experimentações, deslocando a prioridade das evidências experimentais para a criatividade humana.

Há uma história rica em serendipidade na ciência, em todos os campos que nos dispusermos a analisar. Os autores discutem algumas descobertas realizadas de forma não intencional, nos fazendo concluir que o método científico não é o responsável pelo avanço da ciência.

Apesar da serendipidade se mostrar como importante parte da ciência no mundo real, o fato não é considerado na idealizada descrição do método científico como "os passos que levam ao conhecimento científico". Pelo fato de que a serendipidade é um acontecimento acidental, envolvendo chance, oportunidade, intuição e inspiração, ela não pode ser ensinada nem prescrita em nenhum processo. (BROWN E KUMAR, 2013, p. 2).

Como muitos estudiosos costumam afirmar, se o método científico existisse, esse seria revelado através de um estudo histórico das disciplinas ditas científicas. E foi justamente o que os autores se propuseram a fazer na área da física; contudo, após os autores pesquisarem estudos de Bacon até o presente, não encontraram evidência de "nenhum método único que abrangesse todas as descobertas científicas" (BROWN E KUMAR, 2013, p. 2).

Por fim, o estudo de Tang et al. (2010), foi sobre concepções do método científico e investigação científica entre estudantes e professora de uma turma, em uma escola estadunidense, durante uma aula de ciências (90 minutos). Essa aula foi toda gravada e posteriormente se analisou o áudio com as discussões. A autora percebeu que tanto os estudantes quanto a professora estavam sendo limitados nas suas investigações ao seguir as etapas do método científico: 
O método científico, quando visto como rígido, decomposto em passos, não apenas contribui para limitar a pesquisa, como também pode distrair os estudantes e professores da tentativa de realizar uma investigação científica de qualidade. (TANG ET AL., 2010, p. 5)

Segundo a autora, o método simplista e descontextualizado tornou "fazer ciência" algo fácil para se ensinar, por isso a dificuldade em abandonar o esquema. Tang et al. postula que "a aproximação mais produtiva da investigação científica não pode ser introduzindo aos estudantes os passos descontextualizados". A autora afirma que mesmo as versões mais sofisticadas podem demarcar a investigação e angustiar os estudantes, os fazendo focar apenas nas etapas, de forma mecanicista, ao invés do que poderia ser encontrado (TANG et al., 2010). Podemos perceber que suas ideias são contrárias ao que defendeu Herreid (2010), pois o último apresentou o fluxograma criado por profissionais da Universidade de Berkeley como melhor alternativa no ensino do método científico. O modelo de Berkeley, apesar de não ser chamado de "método científico", é uma forma mais complexa e aprimorada do mesmo.

Para Tang et al., a alternativa seria, a princípio, não formalizar os questionamentos dos estudantes; isto é, apenas ir direcionando seu raciocínio. Nesse ponto, a autora usa concepções do brainstorming: uma técnica de criatividade em grupo, cuja intenção é encontrar conclusões para um problema específico através de uma lista de ideias espontâneas sugeridas pelos membros. Ela afirma que, durante uma atividade de brainstorming, se consegue uma investigação produtiva, sem precisar se deter aos passos do método científico (TANG et al., 2010). Contudo, a autora pontua que o máximo que os professores podem fazer - até o momento - é utilizar a prática paralelamente ao ensino do método cientifico; pois, a maioria dos estudantes precisam realizar testes padronizados cujo conteúdo avalia as noções formais do método.

Retomando os pontos principais dos artigos analisados, podemos perceber que os autores concordam em vários aspectos. Todos ressaltaram que o método científico: não é universal; não segue etapas pré-definidas; não é linear. Ao contrário, segundo os mesmos, a investigação científica é complexa, depende da criatividade do pesquisador, além das descobertas não intencionais - que independe do método. Muitas vezes a almejada objetividade, inclusive, pode limitar o processo da investigação.

Loor (2015) defende que devemos deixar de usar o termo "método científico", concordando com Brown e Kumar (2013), Alexakos (2010), Woodcock (2014) que defendem o abandono do uso do método em etapas, definindo o método científico como "mito".

Os outros autores, Herreid (2010), Castillo (2013) e Tang et al. (2010), também problematizam o método científico tradicional; contudo, não sugerem explicitamente o abandono do termo. Os três ofereceram alternativas para o método científico, por considerá-lo simples e generalista. Herreid nos apresenta o modelo em fluxograma desenvolvido por profissionais (filósofos, professores e cientistas) da Universidade de Berkeley; Castillo menciona o model-based inquiry, assim como também cita o modelo de Berkeley e Tang et al. discute sobre o uso de atividades brainstorming nas aulas de ciências a fim de favorecer o uso da criatividade na investigação científica, ou invés de começar as pesquisas introduzindo o tradicional método em etapas.

Como pôde ser observado no presente estudo, apesar da pesquisa ter recuperado alguns artigos, todos eles são de estudos estrangeiros. Pelo que a literatura brasileira evidencia, o ensino do método científico no país é pouco atingido por tais questionamentos, 
imprescindíveis para uma educação científica problematizadora e crítica. É urgente a necessidade de começarmos a problematizar a validade do método científico junto aos estudantes.

Pensamos que, muitas vezes, o termo "método científico" se funde com a própria noção de ciência, por ser esse o método identificado como "responsável" pela produção dos conhecimentos científicos - talvez seja esse o motivo de haver discussões somente sobre a ciência e não sobre o método. Muitas discussões questionando a ciência e seus efeitos na sociedade são feitas através de trabalhos do campo dos Estudos Culturais da Ciência. Esses estudos demonstram que a prática é cercada por mitos e dogmatismos, que devemos sempre ser críticos frente a fatos e explicações científicas e nunca aceitá-las como mais verdadeiras ou mais objetivas do que outras explicações (WORTMANN; VEIGA-NETO, 2001).

Muito do que consideramos ser resultado da objetividade científica, na verdade, é resultado da influência causada pela configuração histórica, cultural e social na qual os pesquisadores estavam situados. Com o método científico tradicional não é diferente: como foi dito brevemente na introdução deste artigo, provavelmente, este foi popularizado por ser inserido nos currículos escolares das instituições de ensino estadunidenses, no início do século XX, justamente pelas necessidades da época em inserir mais conhecimentos e práticas científicas no cotidiano escolar. A quem interessar, sugerimos a leitura do livro de John Dewey, intitulado How We Think, apontado por estudiosos por ser a obra responsável por ter difundido o método científico em etapas (RUDOLPH, 2005).

Podemos então teorizar que o método científico nada mais é do que o resultado de várias tentativas ao longo da história em tentar unificar o conhecimento científico através de um método universal ou "o método ideal". Método esse, como já discutido na introdução desde trabalho, que aparentemente não fora seguido à risca por nenhum dos grandes cientistas, de nenhuma das áreas do conhecimento.

\section{Considerações finais}

Apesar de haver muitos artigos mostrando que professores de ciências e estudantes (educação básica e superior) apresentam uma visão deformada do que seria o método científico (CASTRO e GOLDSCHMIDT, 2016; GIL-PÉREZ, 2001; HARRES, 1999; MARTINS, 1990), poucos são aqueles que aprofundam a temática a fim de mostrar o porquê de não ser possível reduzir a prática científica à um método universal e linear.

A intenção da presente investigação foi de justamente procurar artigos que desenvolvessem uma discussão mais detalhada sobre o tema e encontramos poucos, evidenciando a necessidade de mais produção acadêmica sobre a temática. Dentre esses que recuperamos na busca, de modo geral, os autores defendem que o modo de proceder em investigações científicas depende mais do uso do raciocínio, criatividade, estudo e apoio em evidências - que não precisam ser obrigatoriamente experimentais ou laboratoriais - do que seguir um método generalista e unidirecional.

É necessário que sejam feitos mais estudos e que sejam produzidas mais ações educativas sobre o tema. Podem ser boas iniciativas, por exemplo, pesquisas sobre o cotidiano escolar e a relação dos estudantes e professores com o método científico e/ou sua aplicação em pesquisas escolares. Ou então oficinas e minicursos que discutam, contestem e coloquem "em xeque" o tal método. Não podemos apenas deixar de 
mencionar o método científico, precisamos sim discutir sobre o mesmo: devemos problematizá-lo e utilizá-lo como exemplo de conceitos e fatos equivocados difundidos sob a proteção do que é chamado de "científico".

\section{Referências}

ALEXAKOS, K. Teaching the practice of science, unteaching the "scientific method". Science Scope, Vol.33(9). 2010.

BROWN, R. A.; Kumar, A. The scientific method: reality or myth? Journal of College Science Teaching, Vol.42(4), 2013.

CASTILLO, M. The scientific method: a need for something better? AJNR. American journal of neuroradiology, Vol.34(9), 2013.

CASTRO, T. F.; GOLDSCHMIDT, A. I. Aulas práticas em ciências: concepções de estagiários em licenciatura em biologia e a realidade durante os estágios. Amazônia | Revista de Educação em Ciências e Matemática | v.13 (25), p.116-134. 2016.

CHALMERS, A. F. O que é ciência afinal? Tradução: Raul Filker: 1ª . Ed. - São Paulo: Brasiliense, 1993.

CHASSOT, A. Alfabetização científica: questões e desafios para a educação. ljuí: Ed. Unijuí. 2010.

FARIAS, L. N.; MIRANDA, W. S.; FILHO, S. F. P. Fundamentos epistemológicos das relações cts no ensino de ciências. AMAZÔNIA - Revista de Educação em Ciências e Matemáticas V.9 - no 17, p.63-75. 2012.

FEYERABEND, P. Contra o método. $3^{a}$. edição. Tradução de Cezar Augusto Mortari. SP: Editora Unesp, 2007.

HARRES, J.B. Uma revisão de pesquisas nas concepções de professores sobre a natureza da ciência e suas implicações para o ensino. Investigações no ensino de ciências. v.4, n.3. 1999

HAYASHI, M. C. Sociologia da ciência, bibliometria e cientometria: contribuições para a análise da produção científica. In: EPISTED - Seminário de Epistemologia e Teorias da Educação. Faculdade de Educação/Unicamp. 2012.

HERREID, C. The Scientific Method Ain't What It Used to Be. Journal of College Science Teaching, Vol.39(62), 2010.

KAMPOURAKIS, K. Newton's Apple and other Myths about Science. Harvard Press. 2015.

KRASILCHIK, M., MARANDINO, M. Ensino de Ciências e Cidadania. 2a ed. São Paulo: Editora Moderna. 2007.

LOOR, R. A.C. El método científico, una utopía. Revista Electrónica Formación y Calidad Educativa, Vol.3(2), 2015.

LYOTARD, J. F. A condição pós-moderna. Trad. Ricardo Corrêa Barbosa. 7. ed. Rio de Janeiro: José Olympio, 2002. 
MARTINS, R. A. Sobre o papel da história da ciência no ensino. Boletim da Sociedade Brasileira de História da Ciência. 1990.

MCCOMAS, W. F. Ten Myths of Science: Reexamining What We Think We Know About the Nature of Science. School Science and Mathematics. Volume 96(1). 1996

MOREIRA, M. A.; OSTERMANN, F. Sobre o ensino do método científico. Cad.Cat.Ens.Fís., v.10, n.2: p.108-117, ago.1993

NORONHA, D. P.; FERREIRA, S. M. S. P. Revisões de literatura. In: CAMPELLO, B. S.V. C.; CENDÓN, B. V.; KREMER, J. M. (Org.). Fontes de informação para pesquisadores e profissionais. Belo Horizonte: UFMG, 2000.

NUMBERS, R., KAMPOURAKIS, K. Newton's Apple and other Myths about Science. Harvard University Press. 2015.

PICHETH, F. M. PeArte: um ambiente colaborativo para a formação do pesquisador que atua no ensino superior por meio da participação em pesquisas do tipo estado da arte. 2007. 139 f. Dissertação (Mestrado em Educação) — Pontifícia Universidade Católica do Paraná, Curitiba, 2007.

RUDOLPH, J. L. Epistemology for the Masses: The Origins of "The scientific method". History of Education Quarterly, Vol.45(3), 2005.

SILVA, T. T. "O adeus às metanarrativas educacionais". In: SILVA, T. T. (org.). O sujeito da educação: estudos foucaultianos. Petrópolis: Vozes, 1994.

TANG, X; COFFEY, J. E. ; ELBY, A. ; LEVIN, D. M. The Scientific Method and Scientific Inquiry: Tensions in Teaching and Learning. Science Education,Vol.94(1), 2010.

VOSGERAU, D. S.; ROMANOWSKI, J. P. Estudos de revisão: implicações conceituais e metodológicas Rev. Diálogo Educ., Curitiba, v. 14, n. 41, p. 165-189, jan./abr. 2014

WOODCOCK, Brian A. "The Scientific Method" as Myth and Ideal. Science \& Education, Vol.23(10), p.2069(25). 2014.

WORTMANN, Maria Lucia C.; VEJA-NETO, Alfredo. Estudos Culturais da Ciência. Belo Horizonte, 2001. 